\title{
Preflex Prestressing Technology on Steel Truss Concrete-Composite Bridge with Medium Span
}

\author{
Tang Hui ${ }^{1}$, Wei Wenlong ${ }^{1} \&$ Cui Xiupeng ${ }^{1}$ \\ ${ }^{1}$ Department of Civil Engineering, Chongqing Jiaotong University, Chongqing, China \\ Correspondence: Tang Hui, Department of Civil Engineering, Chongqing Jiaotong University, Chongqing 400074, \\ China. Tel: 86-150-2370-2531. E-mail: tanghuibridge@163.com
}

Received: November 5, 2013

Accepted: December 23, 2013 Online Published: January 9, 2014

doi:10.5539/mas.v8n1p113

URL: http://dx.doi.org/10.5539/mas.v8n1p113

\begin{abstract}
Guangdong Qingqiyong bridge is a prefabricated steel truss-concrete composite continuous rigid frame bridge with a span arrangement of $41 \mathrm{~m}+70 \mathrm{~m}+41 \mathrm{~m}$, to prevent cracks of concrete deck on the bridge pier top section, prestress tendons are usually arranged inside of the concrete deck, after the connection between deck panels and steel truss, prestress tendons are tensioned to make deck compressed, it has been proved that this conventional prestress method is tedious for construction and it also results in a significant loss of prestress. In addition, stress of the top chords in the pier top section is very small in all construction stages, mainly ranges from -60 MPa to $50 \mathrm{MPa}$, thus failed to make full use of its material properties; therefore, preflex prestressing technology of steel truss concrete composite bridge (PPSC in short) was put forward based on preflex prestressing technology, then the detailed analysis was conducted. To validate the feasibility of PPSC, another case study-Wanzhou Bridge was carried out. Results show that the PPSC technology is feasible and it can avoid the use of prestress tendon, simplify the construction, make deck panels get the expected compressive stress easily and make full use of steel properties.
\end{abstract}

Keywords: steel truss-concrete composite, preflex prestress, precast deck, continuous rigid frame bridge

\section{Introduction}

Guangdong Qingqiyong Bridge, crossing Qingqiyong River, is a prefabricated steel truss-concrete composite continuous rigid bridge with a span arrangement of $41 \mathrm{~m}+70 \mathrm{~m}+41 \mathrm{~m}, 4$ traffic lanes and a height-varying truss. The truss height changes following a parabola of 1.8 times with the heights of $6 \mathrm{~m}$ and $2 \mathrm{~m}$ in the pier top and mid-span respectively. The general layout of Qingqiyong Bridge is shown in Figure 1.
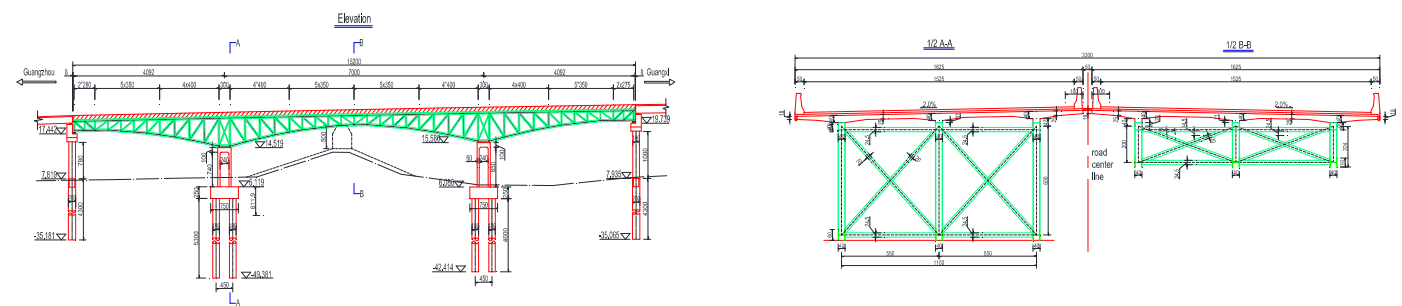

Figure 1. General layout of Qingqiyong Bridge (cm)

The top chords cross section was fabricated as build-up members with flange plates measuring $400 \mathrm{~mm}$ wide by $14 \mathrm{~mm}$ thick; the web plates measured $500 \mathrm{~mm}$ tall by $14 \mathrm{~mm}$ thick; using Q345 steel. Shear studs are welded on the upper surface of top chord with a constant distance of $2.5 \mathrm{~m}$. The precast deck is $5 \mathrm{~m}$ long by $16.25 \mathrm{~m}$ wide, using $\mathrm{C} 50$ concrete. Shear pockets are reserved in the precast deck with a constant distance of $2.5 \mathrm{~m}$ (Brackus, Barr, \& Cook, 2013). The construction of a standard precast deck is shown in Figure 2. 


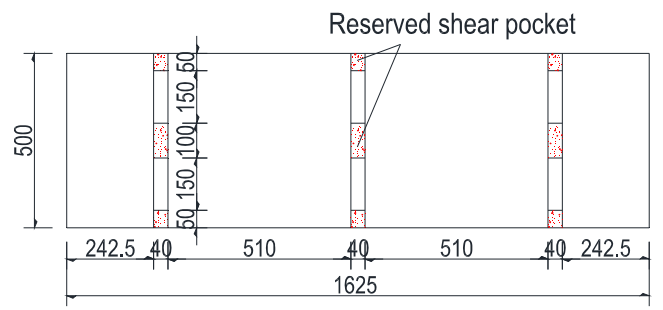

Figure 2. Construction of standard precast deck

The main construction procedures of the conventional prestressed steel truss-concrete composite bridge are as follows:

Step 1: Install the steel truss and precast deck panels in place;

Step 2: Cast expansion concrete in the reserved shear pockets to form shear connector;

Step 3: Tension each batch of prestress tendon from the pier top to both ends after $90 \%$ of the expansion concrete strength.

Totally, there are seven batches of precast deck and six batches of prestress tendon with $1 \mathrm{~m}$ later poured band reserved as closure segment in the mid-span of intermediate span. Figure 3 shows the layout of deck and prestressing, where $\mathrm{P}_{i}$ means $i^{\text {th }}$ batch of prestress, $\mathrm{D}_{i}$ means $i^{\text {th }}$ batch of deck.

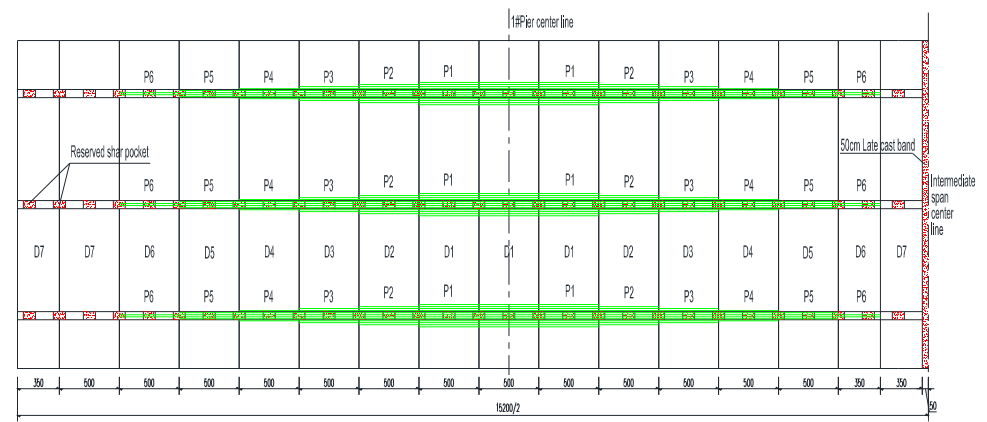

Figure 3. Deck and prestress layout

In the conventional prestressing method, a batch of prestress need to be tensioned after each batch of deck installed that makes construction tedious. Besides, construction for prestress anchorage should be specially considered for the precast deck. In addition, the shear connector is cast at first to make deck and steel truss as a whole, then the prestress tendon is tensioned thus part of the prestress is applied to steel truss which leads to a great loss of prestress.

\section{Finite-Element Model Analysis of the Conventional Prestressed Qingqiyong Bridge}

A FEM of the conventional prestressed steel truss-concrete composite bridge was created using Midas Civil 2012. According to the local climatic condition, two temperature load conditions were considered, with system temperature rising by $19{ }^{\circ} \mathrm{C}$ and falling by $26{ }^{\circ} \mathrm{C}$, respectively. And the vehicle load was modeled through 2 lanes of offset load.

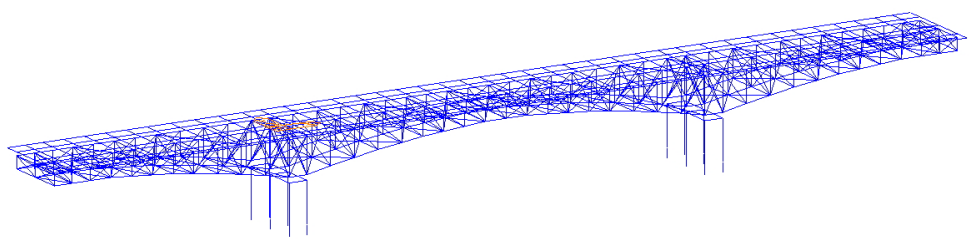

Figure 4. FEM of Qingqiyong Bridge 
Four load effect combinations:

1) Load effect combination 1: $S_{1}=\sum_{\mathrm{i}=1}^{\mathrm{m}} S_{\text {Gik }}$

2) Load effect combination 2: $S_{2}=\sum_{\mathrm{i}=1}^{\mathrm{m}} S_{G i k}+S_{Q 1 k}$

3) Load effect combination 3: $S_{3}=\sum_{\mathrm{i}=1}^{\mathrm{m}} S_{G i k}+S_{Q 1 k}+S_{Q 2 k}$

4) Load effect combination 4: $S_{4}=\sum_{\mathrm{i}=1}^{\mathrm{m}} S_{G i k}+S_{Q 1 k}+S_{Q 3 k}$

where, $S_{i}$ : load effect combination value;

$S_{G i k}$ : characteristic value of $i^{\text {th }}$ permanent load;

$S_{Q 1 k}$ : characteristic value of vehicle load;

$S_{Q 2 k}$ : characteristic value of system temperature rising;

$S_{Q 3 k}:$ characteristic value of system temperature falling;

Figure 5 illustrates the most unfavorable half bridge deck stress under four load effect combinations. The full bridge is symmetric, $0 \mathrm{~m}$ on $\mathrm{X}$-axis represents the center location of $1 \#$ pier, $-41 \mathrm{~m}$ represents the location of $0 \#$ abutment, and $35 \mathrm{~m}$ represents the mid-span of the intermediate span.

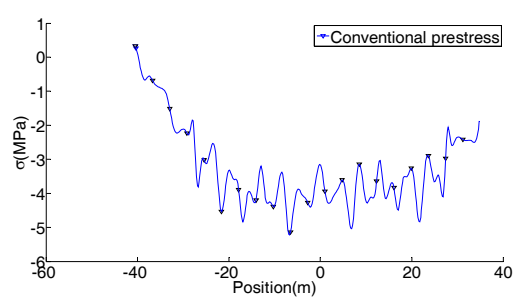

a) Load effect combination 1

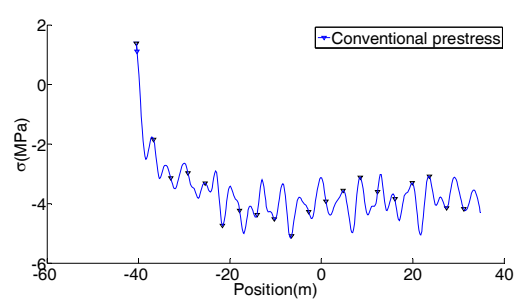

c) Load effect combination 3

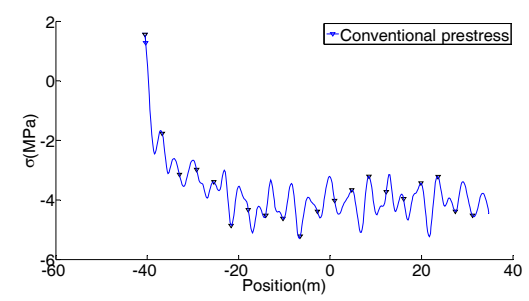

b) Load effect combination 2

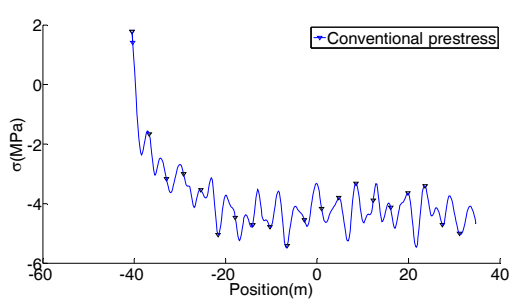

d) Load effect combination 4

Figure 5. Half bridge deck stress under four load effect combinations

Figure 5 shows that the deck stress changes evenly, mainly around $4 \mathrm{MPa}$. As no prestressing tendon was arranged close to the girder end section, the deck compressive stress is small and local tensile stress appeared.

Figure 6 illustrates the most unfavorable steel truss stress of half bridge under four load effect combinations. Similarly, $0 \mathrm{~m}$ on X-axis represents the center location of $1 \#$ pier, $-41 \mathrm{~m}$ represents the location of $0 \#$ abutment and $35 \mathrm{~m}$ represents the mid-span of the intermediate span. 


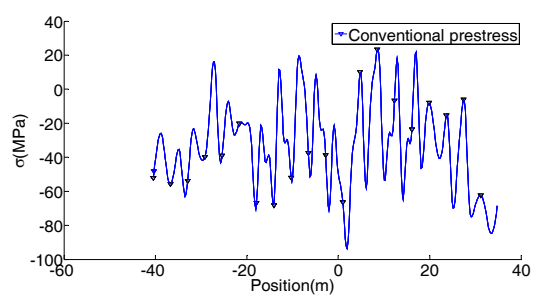

a) Load effect combination 1

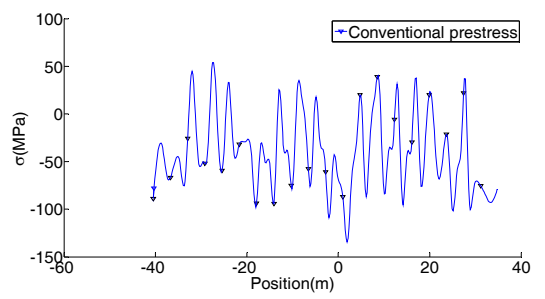

c) Load effect combination 3

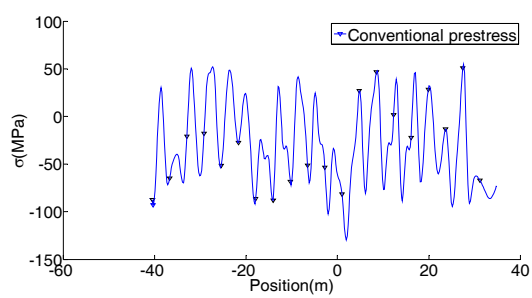

b) Load effect combination 2

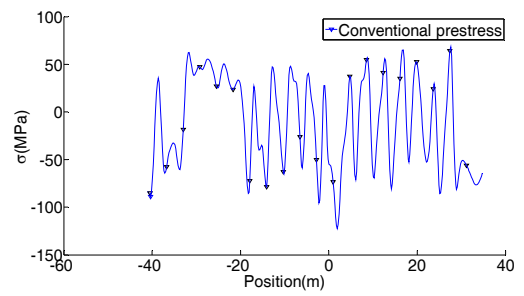

d) Load effect combination 4

Figure 6. Top chord stress of half bridge under four load effect combination

Because of the effect of prestressing force, stress level of the top chords is very low in all construction stages and changing unevenly from $-60 \mathrm{MPa}$ to $50 \mathrm{MPa}$, besides, the compressive stress even reached $-120 \mathrm{MPa}$ at the pier top section as is shown in Figure 6. In this case, steel properties can't be fully developed, but to meet the construction requirements, the cross section and plate thickness cannot be reduced further.

Extensive investigation has been done concerning preflex prestressing, results show that the preflex prestressing are usually used in continuous girder bridge (Nie, 2011). It has been found that the preflex prestressing is also suitable for this type of bridge and it has some advantages by comparison with conventional prestress, therefore, the Preflex prestressing technology of steel truss-concrete composite bridge (PPSC in short) was put forward on the basis of preflex prestressing method, however, the construction procedures are somehow different from that of used in continuous girder bridge, therefore, is worth writing a paper to demonstrate the feasibility and its advantages of PPSC technology on the one hand, and to describe the PPSC construction procedures in detail so that it can provide some references to the design of bridges of like on the other.

\section{Methodological Approach}

To explore the feasibility of PPSC, a computational approach was adopted to assist with understanding the mechanical behavior of bridge. A spatial finite element model (FEM) of Qingqiyong Bridge consisting of the concrete deck, steel truss, pier columns and caps was created in Midas Civil 2012 to investigate the mechanical behavior of PPSC Bridge is rational or not. In this paper, stress comparisons of deck panels and top chord were carried out in terms of the PPSC method and the conventional prestress method.

Of course, provided that results of first case indicate that the PPSC is feasible, a single case study is still not enough to make a conclusion that PPSC is feasible. Therefore, another case study was carried out using computational approach to validate the feasibility of PPSC. In the second case, Wanzhou Bridge, which is the same type with Qingqiyong Bridge, was chosen, a FEM analysis was conducted to get the stress comparisons of deck panels, top chord, bottom chord and bracket in terms of the PPSC method and the conventional prestress method. Finally, compare results obtained from two cases and check whether they are parallel or not.

\section{Preflex Prestressing Technology of Steel Truss-Concrete Composite Bridge (PPSC)}

\subsection{Brief Introduction to the Principle of Preflex Prestressing}

For statically determinate structure system, the vertical displacement of bearings has a great influence on the internal force and stress distribution of structure. According to this principle, relative height of bearings of continuous girder bridge are adjusted before and after the cast of concrete, thus to form pre-compressive stress in concrete (Nie, 2011). 


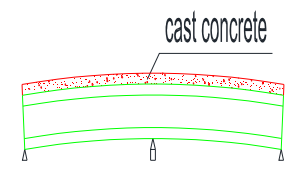

a) Preflex steel beam and cast concrete

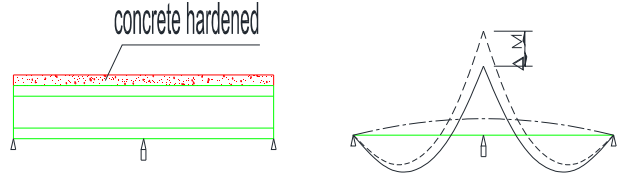

b) Lower intermediate support

Figure 7. Principle of preflex prestressing

\subsection{Main Construction Procedures of PPSC}

According to an un-prestressed steel truss-concrete composite bridge model (other conditions are the same as the previous one), the dividing line of positive and negative moment is about $22 \mathrm{~m}$ to the pier center location on both sides of pier. To realize the PPSC,

Step 1: After the installation of truss girder, the 5th 7 th batch of deck panels (deck in the positive moment section) are installed, and shear connector in this section are cast accordingly;

Step 2: Wedge blocks are set on the upper surface of top chords in the negative moment section and the 1st 4 th deck panels are installed forming a micro arch;

Step 3: Unset wedge block, tension the arch deck downward, cast shear connector in this section accordingly.

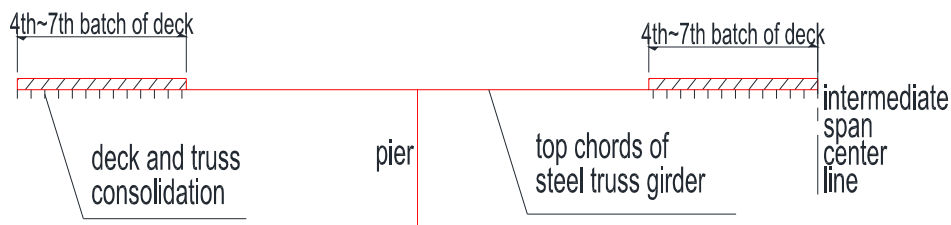

a) Install the 5 th $\sim 7$ th batch of deck panels, cast shear connector accordingly

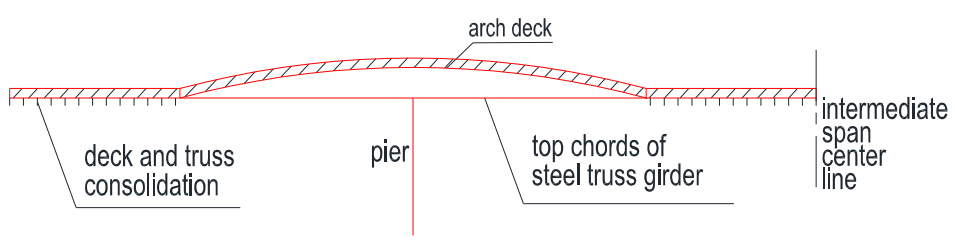

b) Set wedge blocks, install the 1st $\sim$ th (arch deck)batch of deck panels

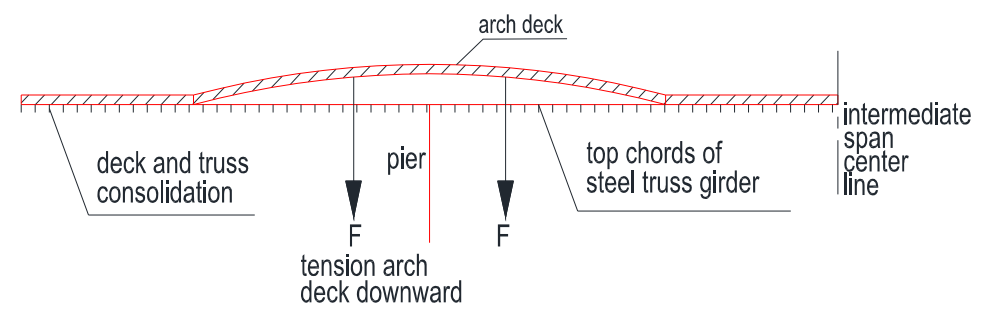

c) Tension the arch deck downward, cast shear connector accordingly

Figure 8. PPSC construction steps

\subsection{The Length Calculation of Arch Deck}

Schematic diagram of the arch deck length calculation is shown in Figure 9. 


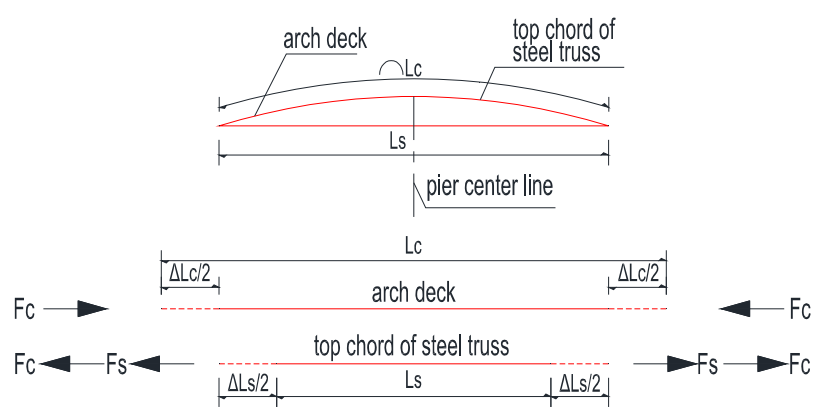

Figure 9. Schematic diagram of arch deck length calculation

The steel truss members are mainly subjected to axial force that influences from the other members to top chords can be neglected in the preliminary calculation and the effects of bending moment to steel truss girder are ignored, that is, the top chord is assumed subject to axial tension merely. In addition, the deck panels and steel truss are consolidated by shear connector assuming deck is subject to axial compression merely.

Assume that $F_{s}$ represents the axial force of top chord without prestress in model, $F_{c}$ represents the expected pre-compressive stress of deck.

By Hooke's law

$$
\Delta l=\frac{F_{\mathrm{N}} l}{E A}
$$

So

$$
\begin{gathered}
\Delta_{\mathrm{c}}=\frac{F_{\mathrm{c}} l_{c}}{E_{c} A_{c}} \\
\Delta_{\mathrm{s}}=\frac{\left(F_{s}+F_{\mathrm{c}}\right) l_{c}}{E_{s} A_{s}}
\end{gathered}
$$

Where $l_{c} \Delta_{c}, l_{s}, \Delta_{s}$ are the length and elongation of concrete deck and steel truss top chord, respectively. $A_{c}, E_{c}, A_{s}, E_{s}$ are the area and elastic modulus of concrete deck and steel truss top chord, respectively.

According to deformation compatibility

$$
l_{c}-\Delta_{c}=l_{s}+\Delta_{s}
$$

By Formula (2), (3) and (4), the deck length is derived as

$$
l_{c}=\frac{E_{c} A_{c}\left(E_{s} A_{s}+F_{c}+F_{s}\right)}{E_{s} A_{s}\left(E_{c} A_{c}-F_{s}\right)} l_{s}
$$

\subsection{Finite-Element Model Analysis of the Preflex Prestressed Qingqiyong Bridge}

A FEM of the preflex prestressed Qingqiyong Bridge was created using Midas Civil 2012. The conditions are the same as the previous one except for the prestress. In the FEM, the length of arch deck is the same as that of the top chord in the corresponding section. The elongations of the arch deck are modeled by rising suitable temperature of the arch deck. The expected compressive stress of deck is $1 \mathrm{MPa}$ in the most unfavorable load effect combination. According to Formula (5) get $\Delta_{c}=22.7 \mathrm{~cm}$, then the temperature of the arch deck should be raised by $50.44^{\circ} \mathrm{C}$. Here $60^{\circ} \mathrm{C}$ was used in the model. On the basis of initial calculation, the thickness of steel pate is partly adjusted. In $-9.5 \mathrm{~m} \sim 13.5 \mathrm{~m}$ section, the plate thickness is increased from $14 \mathrm{~mm}$ in the previous to $18 \mathrm{~mm}$, and in $-3.5 \mathrm{~m} \sim 6.5 \mathrm{~m}$ section, inside surfaces of steel box are stiffened with 8 longitudinal stiffeners measuring $50 \mathrm{~mm}$ wide by $18 \mathrm{~mm}$ thick. In addition, the cross sections of bottom chords where stress partially increased are strengthened accordingly.

Figure 10 illustrates the most unfavorable half bridge deck stress under four load effect combinations, similarly, the full bridge is symmetric. $0 \mathrm{~m}$ on $\mathrm{X}$-axis represents the center location of $1 \#$ pier, $-41 \mathrm{~m}$ represents $0 \#$ abutment, and $35 \mathrm{~m}$ represents the mid-span of intermediate span. 


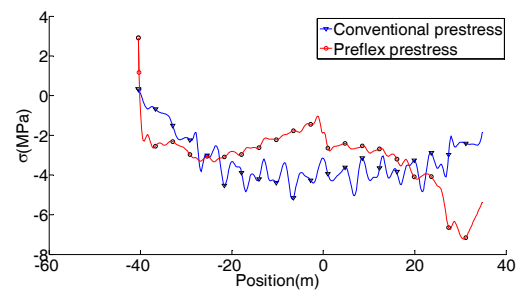

a) Load effect combination 1

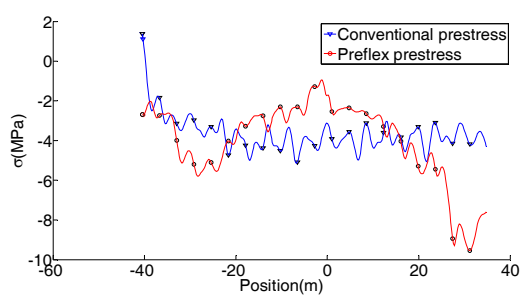

c) Load effect combination 3

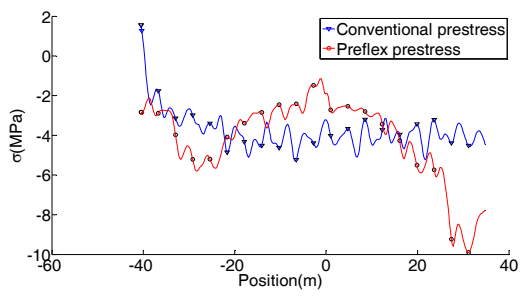

b) Load effect combination 2

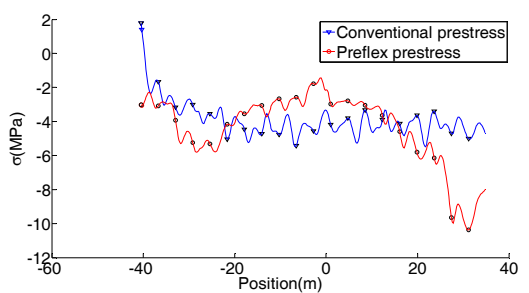

d) Load effect combination 4

Figure 10. Deck stress compassion under for load effect combination

Contrast to the conventional prestress, PPSC makes the top chord act as external prestress to deck. It can be concluded that changes of deck stress increased, for that the 1st-4th deck formed a micro arch after deformation, the horizontal force of arch foot further increased the deck compressive stress in the positive moment section with the maxim of $-9 \mathrm{MPa}$. In the pier top section, preflex prestress are partly applied to steel truss and results in a reduction of compressive stress in deck, with the minimum stress of $-1 \mathrm{MPa}$, no tensile stress appeared in girder end. Provided that the cross section and length of both top chords and decks are properly adjusted, the expected compressive stress in decks can be easily achieved.

Figure 11 illustrates the most unfavorable steel truss stress of half bridge under four load effect combinations, the full bridge is symmetric. $0 \mathrm{~m}$ on $\mathrm{X}$-axis represents the center location of $1 \#$ pier, $-41 \mathrm{~m}$ represents $0 \#$ abutment, and $35 \mathrm{~m}$ represents the mid-span of intermediate span.

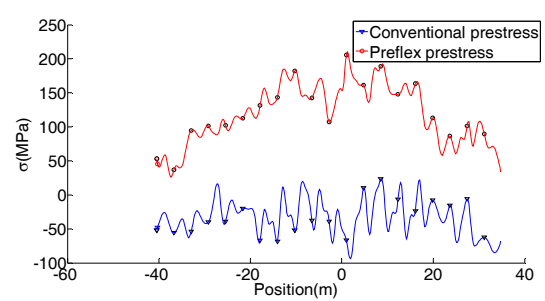

a) Load effect combination 1

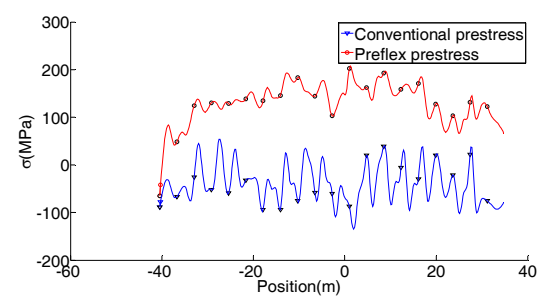

c) Load effect combination 3

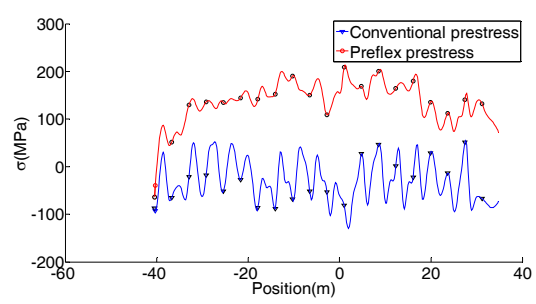

b) Load effect combination 2

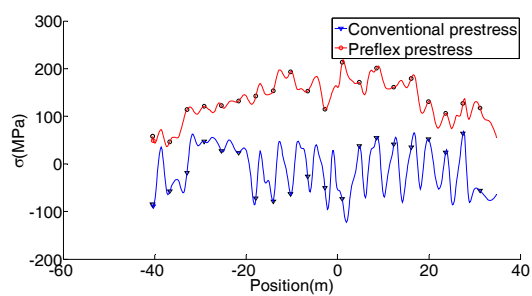

d) Load effect combination 3

Figure 11. Stress comparison of top chords under four load effect combination

Compared with the conventional prestressed steel truss-concrete composite bridge, PPSC makes top chords stress change evenly in all construction stages. In the pier top section, the effects of preflex prestress combined 
with bending moment effect makes truss stress maximally reaches $213 \mathrm{MPa}$. The top chords stress mainly ranges from $120 \mathrm{MPa}$ to $200 \mathrm{MPa}$ that fully developed the material properties.

\section{Another Case Study - Wanzhou Bridge to Validate the Feasibility PPSC}

On the basis of Qingqiyong Bridge, PPSC technology was put forward, the best way to validate its feasibility is to apply it to other bridges of like, and then to check whether the mechanical performance of the whole bridge is rational or irrational. Therefore, another FEM of Wanzhou Bridge was created using Midas 2012, as is shown in Figure 12. Wanzhou Bridge, with a span arrangement of $75 \mathrm{~m}+120 \mathrm{~m}+75 \mathrm{~m}$, is also a steel truss-concrete composite continuous rigid bridge, located in Chongqing City and opened to traffic in 2001. The top chords, bottom chords and triangle brackets were made of steel tube concrete with diameters of $450 \mathrm{~mm}, 500 \mathrm{~mm}$ and $600 \mathrm{~mm}$, respectively.

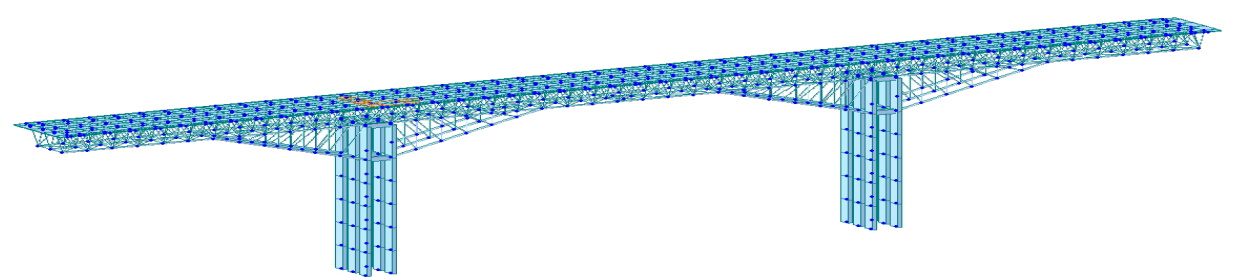

Figure 12. The FEM of Wanzhou Bridge

In the FEM, both PPSC and the conventional prestress method were modeled, and PPSC was modeled by rising the element temperatures $\left(50{ }^{\circ} \mathrm{C}\right)$ of the 1 st to 5 th batches of deck panels, Figure 13 illustrates the stress comparison of different members of Wanzhou Bridge (Load effect combination: dead load + live load). The full bridge is symmetric, $0 \mathrm{~m}$ and $120 \mathrm{~m}$ on X-axis represent the center location of $1 \#$ pier and 3\# pier, respectively, $-75 \mathrm{~m}$ represents $0 \#$ abutment, $60 \mathrm{~m}$ represents the mid-span of intermediate span.

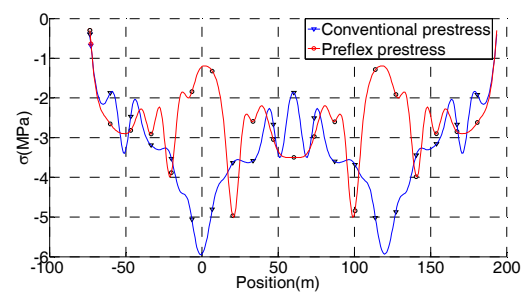

a) Deck stress comparison

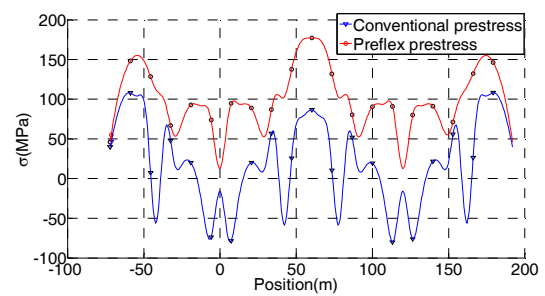

c) Bottom chord stress comparison

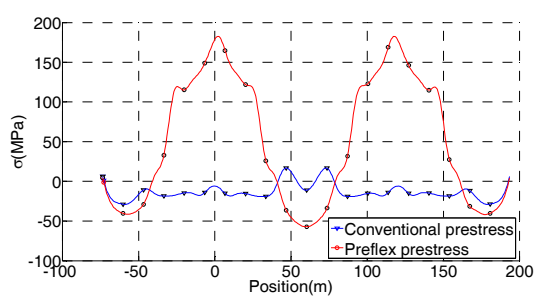

b) Top chord stress comparison

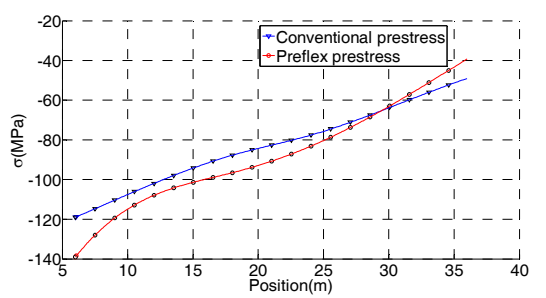

d) Steel tube bracket stress comparison

Figure 13. Stress comparison of Wanzhou Bridge

In the conventional prestress method, the stress of the top chord and the bottom chord are small and mainly in compressive, under the pre-condition that at least $1 \mathrm{MPa}$ compressive stress is reserved in deck panels under load effect combination, PPSC makes the maximum stress of top chord reaches $182 \mathrm{MPa}$, and maximum stress of bottom chord reaches $174 \mathrm{MPa}$, however, the maximum stress of steel tube bracket just increased from $119 \mathrm{MPa}$ to $139 \mathrm{MPa}$.

\section{Discussion}

A single case study was carried out to explore the feasibility of PPSC, the results show that the PPSC technology is feasible and it can avoid the use of prestress tendon, simplify the construction, make deck panels get the 
expected compressive stress easily and make full use of steel properties.

However, it is possible that the results may not be fully right because of modeling method and some assumptions, such as whether it is rational that the deck panels and steel truss were coupled to each other using rigid links. Besides, it is also uncertain that the results obtained from a single case is workable in other cases of like. Therefore, what need to be done is to apply it to other cases of like and check whether it is still workable or not. Here, another case was analyzed, and the results were highly parallel with the previous one, thus it is reasonable to conclude that PPSC is feasible, of course, it is certain that some deviation may exist between the conclusions and the real situations.

Preflex prestressing technology of steel truss concrete composite bridge has many advantages. However, these results are concluded based on two case studies, so the economical span needed to be determined in the further research. Besides, more research should be done concerning the key constructions.

\section{Summary and Conclusions}

With the rapid development of the prefabricated steel truss concrete composite bridge, some disadvantages of conventional prestress method are found relied on Guangdong Qingqiyong Bridge in terms of tedious for construction, a great amount loss of prestress and etc. Therefore, preflex prestressing technology of steel truss concrete composite bridge (PPSC in short) was put forward based on preflex prestressing method and detailed analysis was performed. To validate the feasibility of PPSC, another case study-Wanzhou Bridge was carried out. The results are parallel with that of Qingqiyong Bridge, therefore, the feasibility of PPSC was demonstrated. The following conclusions can be drawn from this research:

1) Provided that the conventional prestress tendons are used, anchorage blocks should be designed in every precast deck, this increases the difficulty of prefabrication. Besides, each batch of prestress tendon should be tensioned and anchored respectively, thus increases the construction procedures. However, anchorage blocks, prestress tension and anchor are no longer needed if PPSC is adopted, once the arched deck is formed, it can be pushed down using a small force thus to realize the pre-compressive stress in deck. Therefore, construction is greatly simplified.

2) The significant features of steel-concrete composite structure is that steel is used to against tension while concrete is used to against compression as much as possible. However, in the conventional prestress method, after each batch of prestress tension, deck is connected to steel truss using shear connector, then the concrete decks join in the steel truss to against negative bending moment in the pier top section, this is not what we are expecting. Unlike the conventional prestress, PPSC makes the top chords of steel truss act as external prestress to precast deck, and steel truss is only one to against negative bending moment in the pier top section. Thus the properties of steel truss-concrete composite structure are fully developed.

3) In the conventional prestress method, rigidity abrupt change is appeared in sections where each two decks joint because of unbalanced prestress tendon and shear connection which results in uneven stress change of top chords. However, in PPSC method, top chords of steel truss act as external prestress to precast deck, the arched decks are connected to steel truss after the uniform elongation of the top chords, so the top chords stress changes evenly. In the conventional prestress method, some the top chords stress is are partly compressive as is shown in Figure 6. In PPSC method, however, the top chords stress is mainly ranges from $120 \mathrm{MPa}$ to $200 \mathrm{MPa}$ as in shown in Figure 11, no compressive stress is appeared, material properties are fully developed.

4) According to the derived Formula (5), in PPSC method, the deck compressive stress is relate to the section area and length of both top chord and deck, therefore, provided that the cross section and length of both top chords and decks are properly adjusted, the expected compressive stress in deck can be easily achieved.

\section{References}

General Code for Design of Highway Bridges and Culverts. (2004). Beijing: Ministry of communications of the People's Republic of China.

Johnson, R. P. (1994). Composite Structures of Steel and Concrete, Vol. 2: Bridges. Oxford: Blackwell Scientific Publications.

Mabsout, M. E., Tarhini, K., Frederick, G. R., \& Tayar, C. (1997). Finite-element analysis of steel girder highway bridges. Bridge Eng., 2(3), 83-87. http://dx.doi.org/10.1061/(ASCE)1084-0702(1997)2:3(83)

Nie, J. (2011). Steel concrete composite bridge. Beijing: China Communications Press.

Sullivan, S. R., Roberts-Wollmann, C. L., \& Swenty, M. K. (2011). Composite behavior of precast concrete 
bridge deck-panel systems. PCI J. Summer, 43-59.

Travis, R. B., Paul, J. B., \& Wesley, C. (2013). Live Load and Shear Connection Testing of Full-Scale Precast Bridge Panels. Bridge Eng., 18(3), 210-219. http://dx.doi.org/10.1061/(ASCE)BE.1943-5592.0000343

$\mathrm{Xu}, \mathrm{J} .$, \& Sun, S. (2011). The steel bridge. Beijing: China Communications Press.

\section{Copyrights}

Copyright for this article is retained by the author(s), with first publication rights granted to the journal.

This is an open-access article distributed under the terms and conditions of the Creative Commons Attribution license (http://creativecommons.org/licenses/by/3.0/). 